Antropología Cuadernos de Investigación, núm. 15, julio-diciembre 2015, pp. 127-129

\title{
Insuficiencia Nutricional en el Ecuador. Causas, Consecuencias y Soluciones, Banco Mundial, 2007
}

$\mathrm{L}$

a presente publicación, en el marco de los Estudios sobre países del Banco Mundial, es un informe realizado con el objetivo de establecer el perfil de la malnutrición en el Ecuador; analizar las causas de la malnutrición crónica en el país; describir los programas nutricionales e identificar sus problemas; y, finalmente, realizar recomendaciones para el "Desarrollo de una Estrategia Nacional de Nutrición Basada en Objetivos".

Los autores plantean que la situación nutricional de Ecuador, genera una gran preocupación ya que, junto a Perú, Bolivia, Honduras y Guatemala, presentan una alta tasa de deficiencias nutricionales infantiles.

Afirman que las causas de la malnutrición en Ecuador están relacionadas con falencias políticas, y que los sectores de salud primaria y nutrición están mal articulados, son propensos a la politización y no prestan suficiente atención a la medición de resultados.

Finalmente expresan que el presente informe "tiene como propósito apoyar al Gobierno en su avance en estos frentes, proporcionando información congruente y actualizada en torno a la naturaleza y alcance del problema"

A partir de la ENDEMAIN 2004 (Encuesta Demográfica y de salud Materno-Infantil), articulada con la Encuesta Nacional de Empleo, Subempleo y Desempleo (ENEMDU 2004), se identifica que el principal problema nutricional es la malnutrición crónica, es decir una deficiencia en la talla-por-edad o "stunting" (23,1 \% de los niños menores de cinco años tiene baja-talla-por-edad y un 5,9\% presenta una baja-talla-por-edad extrema). ${ }^{1}$

En relación a la distribución de la malnutrición según diferentes criterios, se ha encontrado una mayor prevalencia entre los 12 y 23 meses de vida de los niños (28,4\%); en el grupo poblacional indígena (46,6\%), en el sector rural $(30,6 \%)$; en la región de la sierra $(31,9 \%)$; en regiones ubicadas a alturas mayores a los 2499 m.s.n.m. (34,9\%) y en hogares pobres $(27,6 \%)$.

En relación a la deficiencia de micronutrientes, a partir del DANS (Diagnóstico de la Situación Alimentaria, Nutricional y de Salud de la Población Ecuatoriana menor de cinco años) de 1986 y de las evidencias de estudios más recientes, se identifica una alta prevalencia de anemia por deficiencia de hierro en niños menores a dos años y en mujeres en edad fértil; desórdenes por deficiencia de Yodo $^{2}$ y una alta prevalencia de deficiencia de vitamina A en niños.

1 Cabe destacar que en el informe se expresa que los datos son registrados a partir de la norma internacional utilizada por la OMS, pero que a partir del 2006 esta norma ha sido redefinida, frente a lo cual, la tasa reportada, según estos nuevos estándares sería significativamente mayor (28,9\%).

2 Desde los años 80 el Ecuador promueve la yodización de la sal para disminuir estas tasas. 
Existen tres causas inmediatas de la baja-talla-por-edad: ingesta inadecuada de alimentos, bajo peso al nacer, y la incidencia y el manejo de las enfermedades infantiles. Estas causas están interrelacionadas, y se dan a nivel del hogar, comunitario y social.

En relación a los determinantes culturales de la dieta y las prácticas de salud de las poblaciones indígenas, los autores afirman que "los indígenas ecuatorianos no rechazan la atención médica moderna per se" (Banco Mundial, 2007: 61) pero que existen múltiples obstáculos tales como los sistemas de creencias tradicionales, las preferencias culturales, las barreras de lenguaje, el tiempo y costos requeridos para acceder a las alternativas modernas y la mala calidad de muchos de los servicios disponibles.

Por otro lado, el deficiente acceso al agua potable y a los servicios sanitarios, sumado a la falta de hábitos higiénicos, siguen siendo factores principales en el estado nutricional y de salud.

El informe analiza la red de salud del Ministerio de Salud Pública, y concluye que el desafío está "en convertir estos gastos en mejores estadísticas nutricionales" (Ibíd.: 69).

Identifican que se ha trabajado en pos de mejorar la malnutrición con la aprobación de Ley de Maternidad Gratuita (LMG) en 1999, la creación del sistema SISVAN, que monitorea los resultados de crecimiento de los niños en los puestos de salud y de un programa de micronutrientes.

Además el gobierno del Ecuador cuenta con seis programas de distribución de alimentos:

- Programa de Alimentación Escolar (PAE), administrado por el Ministerio de Educación y Cultura.

- Programas administrados o financiados por el Ministerio de Bienestar Social:

- Aliméntate Ecuador;

- Operación Rescate Infantil (ORI);

- Transferencias al Instituto Nacional del Niño y la Familia (INNFA);

- Programa FODI.

- $\quad$ Programa PANN 2000, administrado por el MSP.

En el año 2005 se creó el Sistema Integrado de Alimentación y Nutrición (SIAN), el cual agrupa a tres de los programas (AE, PAE y PANN 2000). En el 2006 se aprobó una nueva Ley de Seguridad Alimentaria, la cual generó cierta confusión con respecto al rol del SIAN, por lo que los autores sugieren que el SIAN se enfoque en intervenciones con miras a mejorar los resultados en la baja-talla-por-edad.

Además el Ministerio de Bienestar cuenta con el Bono de Desarrollo Humano, el cual consideran que sería una oportunidad para articular una estrategia nutricional y de salud a nivel nacional.

Los autores señalan que uno de los factores que provocan la ineficacia de los programas es la inestabilidad presupuestaria a la que están sujetos, además, la cobertura e incidencia del beneficio de los mismos no muestran resultados totalmente satisfactorios, y existen problemas en cuanto a la focalización y aún no se ha logrado un mecanismo óptimo para evaluar el rendimiento de los programas.

Los autores consideran que el SIAN necesita desarrollar una estrategia nacional de nutrición basada en objetivos, la cual trascienda los programas de alimentación y abarque una gran intervención que incluya el control y crecimiento a nivel comunitario, la salud primaria, la suplementación con micronutrientes, y que coordine con las agencias responsables del agua potable y saneamiento.

El presente informe aporta datos importantes a manera de diagnóstico de la situación de la malnutrición infantil en Ecuador y de los programas nutricionales. Pero, considero que si bien se detectan factores socioeconómicos como causas de estas problemáticas, al momento de ofrecer estrategias para las soluciones, no se da el peso que éstas realmente tienen.

Por otro lado, la cuestión cultural, es analizada en pos de contrastar si estas prácticas son acordes o no con la "medicina moderna", privilegiando así esta medicina, cayendo en el 
binarismo biomédico/tradicional, desconociendo la heterogeneidad cultural existente en las prácticas de alimentación y salud.

Finalmente, la ausencia de propuestas ligadas a estrategias que promuevan el aprovechamiento de recursos a nivel local, valorizando los diferentes saberes culturales, niega la pluralidad cultural y desacredita la capacidad de acción por parte de las personas y comunidades a partir de sus propios conocimientos.

Magali Kanterewicz 